Jurnal Media Pertanian Vol. 1 No. 1 Tahun 2016 Hal. 29 - 35

Media Komunikasi Hasil Penelitian dan Review Literatur Bidang Ilmu Agronomi ISSN $2503-1279$

\title{
SULUR PANJAT MERUPAKAN SUMBER STEK TERBAIK UNTUK PERBANYAKAN BIBIT LADA SECARA VEGETATIF
}

\author{
Yulistiati Nengsih $^{1 *}$, Ridawati Marpaung ${ }^{1}$ dan Alkori $^{2}$ \\ ${ }^{1}$ Program Studi Agroteknologi, Fakultas Pertanian Universitas Batanghari \\ Jl. Slamet Riyadi-Broni-Jambi, 36122 Telp. +62074160103 \\ ${ }^{2}$ Alumni Program Studi Agroteknologi, Fakultas Pertanian Universitas Batanghari \\ *email korespondensi : nyulistiati@yahoo.com
}

\begin{abstract}
This research aims to get the best source of cuttings in the production of pepper seedlings. This research has been carried out in the Teluk Raya village of Kumpeh Ulu Subdistrict Muaro Jambi Regency. Research conducted for 3 months beginning in January to March 2015. Environmental complete random design was applied in the research. The design of the treatment is the different cuttings source, as follows: P1: a climbing vine cuttings, P2: fruit vine cuttings, P3: hanging vine cuttings, P4: ground vine cuttings. Each treatment was repeated four times. There are 10 pepper cuttings for each experiment unit, so that there are 160 uniform cuttings which needed in the research. It shold be taken 8 cuttings from the existing 10 cutting. The results of this research rejects the null hypothesis $(\mathrm{HO})$ and receive alternative hypothesis (H1) that pepper seed growth was differ among the source of cuttings. The study also get that climbing vine cuttings was have produce the best pepper germ and significantly differentl fruit vine cuttings, ground vine cuttings and hanging vine cuttings. The predicted superior of pepper cutting sourcing from climbing vine is the high carbohydrat and balance existing of endogen auxin and citokinin hormon, so that show balance of bud and root growth. Those growth both bud and root certaintly support the cutting growth.
\end{abstract}

Keywords: plant reproduction, vegetative propagation, and hormones to grow

\begin{abstract}
Abstrak
Penelitian ini bertujuan untuk mendapatkan sumber stek yang terbaik dalam produksi bibit lada. Penelitian ini telah dilaksanakan di Desa Teluk Raya Kecamatan Kumpeh Ulu Kabupaten Muaro Jambi. Penelitian dilakukan selama 3 bulan dimulai pada bulan Januari sampai Maret 2015. Rancangan lingkungan yang digunakan penelitian ini adalah rancangan lingkungan acak lengkap. Rancangan perlakuan adalah sumber stek yang berbeda, sebagai berikut: $\mathrm{P}_{1}$ : Stek dari sumber sulur panjat, $\mathrm{P}_{2}$ : Stek dari sumber sulur buah, $\mathrm{P}_{3}$ : Stek dari sumber sulur gantung, $\mathrm{P}_{4}$ : Stek dari sumber sulur tanah. Setiap perlakuan yang dicobakan diulang sebanyak 4 kali. Sedangkan setiap satu satuan percobaan terdiri 10 stek lada, berarti stek lada yang seragam yang dibutuhkan dalam percobaan ini berjumlah 160 setek. Dari 10 stek lada pada percobaan, dengan 8 sampel stek. Hasil penelitian ini menolak hipotesis nol $\left(\mathrm{H}_{0}\right)$ dan menerima hipotesis $1\left(\mathrm{H}_{1}\right)$ bahwa pertumbuhan bibit lada berbeda antar sumber stek. Penelitian ini juga mendapatkan bahwa stek sumber sulur panjat menghasilkan bibit lada terbaik dan berbeda nyata dibandingkan stek sumber sulur buah, sulur tanah dan sulur gantung. Dugaan yang mendukung kebaikan stek lada asal sulur panjat adalah kandungan karbohidrat yang tinggi dan adanya keseimbangan hormon endogen auksin dan sitokinin sehingga terjadi kesimbangan pertumbuhan tunas dan akar. Pertumbuhan tunas dan akar inilah yang memacu pertumbuhan stek lada.
\end{abstract}

Kata Kunci : Perbanyakan tanaman, pembiakan vegetatif, dan hormon tumbuh 
Jurnal Media Pertanian Vol. 1 No. 1 Tahun 2016 Hal. 29 - 35

Media Komunikasi Hasil Penelitian dan Review Literatur Bidang Ilmu Agronomi

ISSN $2503-1279$

\section{PENDAHULUAN}

Lada (Piper nigrum, L.) memiliki peran penting dalam perekonomian nasional, yaitu sebagai penyumbang devisa negara, penyedia lapangan kerja, bahan baku industri, dan konsumsi langsung. Devisa dari lada menempati urutan keempat setelah minyak sawit, karet, dan kopi. Indonesia merupakan negara penghasil lada terbesar di dunia, walaupun demikian peningkatan produksi harus tetap dilakukan untuk menambah peluang pasar lada yang sudah ada. Usaha untuk menambah produksi tidak hanya melalui perluasan lahan saja, tetapi juga harus dengan perbaikan dan pengembangan teknik budidaya, seperti : penggunaan varietas unggul, teknik penanaman yang baik, pengairan, pemupukan, dan perlindungan tanaman dari gulma, hama dan penyakit.

Perbanyakan tanaman lada bisa dilakukan dengan cara generatif (biji) dan vegetatif (stek). Perbanyakan dengan generatif biasanya dilakukan oleh lembaga penelitian untuk menghasilkan tanaman hibrida dan varietas baru yang bersifat unggul serta keanekaragaman genetik. Sedangkan, cara perbanyakan vegetatif adalah cara yang paling efektif dan efisien (Nurhakim, 2014). Pada umumnya perbanyakan tanaman lada dilakukan dengan cara vegetatif yaitu stek.

Pembibitan sangat diperlukan sebagai suatu cara untuk menyediakan bahan tanam dalam jumlah banyak. Perbanyakan tanaman lada dengan stek 2 ruas menjadi peluang untuk ketersediaan bahan tanam dengan cepat sehingga mendukumg peningkatan produksi. Ketersediaan bibit dalam jumlah yang banyak menjadi faktor kunci dalam keberhasilan produksi lada.

Pengujian untuk meningkatkan pertumbuhan stek lada telah banyak dilakukan. Suprato (2001) menyatakan bahwa Rootone-F dengan konsentrasi 1,5 g dalam $40 \mathrm{ml}$ air menghasilkan pertumbuhan stek terbaik. Aguzean (2009) mendapatkan pertumbuhan stek lada meningkat $25 \%$ lebih tinggi dibandingkan kontrol bila direndam dalam urine sapi selama 10-15 menit. Begitu juga dengan Budi, Donowarti dan Dianto (2012) yang mendapatkan pertumbuhan stek lada meningkat dengan perlakuan perendaman stek pada air kelapa.

Percobaan-percobaan tersebut menggunakan zat pengatur tumbuh (ZPT) dalam memacu pertumbuhan stek lada dengan satu macam sumber stek. Perlu juga dicari alternatif lain untuk meningkatkan pertumbuhan stek tanpa menggunakan ZPT yaitu dengan cara mencari bagian tumbuh tanaman lada yang bila dijadikan bahan stek akan menghasilkan bibit lada yang baik. Pola pikir ini didasarkan atas adanya perbedaan konsentrasi auksin dari bagian tubuh tanaman yang akan dijadikan stek. Menurut Gardner, Pierce dan Mitchell (1991) auksin diproduksi pada ujung tunas akar dan batang, dengan demikian kandungan auksin dari bahan stek asal sulur panjat, sulur gantung, sulur tanah, dan sulur buah akan berbeda. Kandungan auksin yang tinggi diharapkan dapat memacu pertumbuhan stek lada secara alami tanpa penambahan ZPT. Guna mendapatkan informasi mengenai pertumbuhan stek lada (Piper nigrum, L.) dari berbagai sumber sulur, telah dilakukan percobaan dengan tujuan untuk menentukan sumber stek terbaik untuk menghasilkan bibit lada dari perbanyakan vegetatif.

\section{BAHAN DAN METODE}

Bahan-bahan yang digunakan dalam penelitian ini meliputi: stek lada (Varietas Lampung) dua nodus yang diambil dari kebun masyarakat di Sungai Gelam, tanah Ultisol, sekam, bahan organik (kompos), polybag ukuran kecil $10 \times 15 \mathrm{~cm}$, dan insektisida (Sumialpha 25 C) fungisida (Dithane M-45). Alat-alat yang dipakai meliputi: 
Jurnal Media Pertanian Vol. 1 No. 1 Tahun 2016 Hal. 29 - 35

Media Komunikasi Hasil Penelitian dan Review Literatur Bidang Ilmu Agronomi

ISSN $2503-1279$

cangkul, ember, gunting stek, oven listrik, timbangan analitik, plastik, jangka sorong, meteran, kayu atau bambu, tali, dan pranet.

Rancangan lingkungan yang digunakan penelitian ini adalah rancangan lingkungan acak lengkap. Rancangan perlakuan adalah sumber stek yang berbeda, sebagai berikut. $\mathrm{P}_{1}$ : Stek dari sumber sulur panjat, $\mathrm{P}_{2}$ : Stek dari sumber sulur buah, $\mathrm{P}_{3}$ : Stek dari sumber sulur gantung dan $\mathrm{P}_{4}$ : Stek dari sumber sulur tanah.

Bibit diambil dari tanaman induk, dimana bibit dipotong di dalam wadah atau tempat yang berisi air. Agar bibit tidak mengalami kelayuan dan mati pada saat penanaman. Bibit dipotong sesuai ukuran stek (dua nodus) dan dua daun. Media tanam untuk pembibitan lada adalah tanah Ultisol, sekam, bahan organik (kompos), dan perbandingan $2: 1$ : 1 . Media diaduk sampai tercampur merata, kemudian tanah dimasukan ke polybag ukuran kecil 10 x $15 \mathrm{~cm}$. Media disiram sampai jenuh agar tetap lembab pada saat stek ditanam. Sebelum bibit ditanam pada media tanam, dibuat lobang terlebih dahulu untuk mempermudah penanaman stek. Bibit yang telah ditanam di polybag, dipindahkan ke bedengan yang telah disiapkan. Setelah pemindahan bibit ke bedengan, kemudian bedengan disungkup dengan menggunakan plastic. Penyungkupan ini bertujuan untuk mempercepat pertumbuhan, dan menjaga agar bibit tidak terserang hama dan penyakit.

Kegiatan pemeliharaan stek di pembibitan meliputi penyiraman, penyiangan, pengendalian hama dan penyakit. Penyiraman dilakukan dua hari sekali, sedangkan penyiangan terhadap gulma yang tumbuh di media tanam maupun yang tumbuh di sekitar unit percobaan dilakukan secara manual. Kegiatan yang berhubungan dengan perlindungan tanaman terhadap hama dan penyakit, menggunakan insektisida (Sumialpha 25 C) dan fungisida (Dithane M-45).

Parameter yang diukur pada percobaan ini adalah; 1) Persentase stek lada yang hidup dihitung pada akhir percobaan pada setiap ulangan masing-masing perlakuan, 2) Jumlah akar, jumlah seluruh akar yang tumbuh dihitung pada akhir penelitian pada masing-masing stek pada perlakuan, 3) Panjang akar di ukur pada akhir penelitian, seluruh panjang akar $(\mathrm{cm})$ pada masing-masing stek pada perlakuan dan dirata-ratakan, dengan perhitungan sebagai berikut. Panjang Akar $=\frac{\sum P A}{S}$, dimana PA adalah panjang akar dan $S$ adalah jumlah stek per lot, 4) Jumlah tunas dihitung pada akhir percobaan seluruh tunas yang tumbuh pada masing-masing stek pada setiap perlakuan, 5) Panjang tunas di ukur pada akhir percobaan seluruh panjang tunas yang tumbuh pada stek setiap perlakuan, 6) Jumlah daun dihitung pada akhir penelitian, pada jumlah daun yang tumbuh pada masing-masing stek pada setiap perlakuan, 7) Bobot kering akar ditentukan dengan cara membersihkan akar dari tanah dan kotoran dengan menggunakan air bersih dan dikeringkan dengan menggunakan oven listrik pada suhu $105^{\circ} \mathrm{C}$ selama 2 jam, lalu ditimbang dengan timbangan analitik. Pengeringan dilakukan sampai diperoleh berat konstan, berat kering akan di hitung dengan menggunakan rumus tersebut. Bobot kering akar $=\frac{\sum A K}{S}$, dimana $\mathrm{AK}$ adalah akar kering dan $\mathrm{S}$ adalah jumlah stek per lot, 8) Bobot kering tajuk ditentukan dengan cara membersihkan tajuk dari tanah dan kotoran dengan menggunakan air bersih dan dikeringkan dengan menggunakan oven listrik pada suhu $80^{\circ} \mathrm{C}$ selama 24 jam, lalu ditimbang dengan timbangan analitik. Pengeringan dilakukan sampai diperoleh berat konstan, berat kering tajuk di hitung dengan menggunakan rumus: Bobot kering tajuk $=\frac{\sum A K}{S}$, dimana $\mathrm{AK}$ adalah tajuk kering dan $S$ adalah jumlah stek per lot, 9) Nisbah tajuk akar dilakukan 
Jurnal Media Pertanian Vol. 1 No. 1 Tahun 2016 Hal. 29 - 35

Media Komunikasi Hasil Penelitian dan Review Literatur Bidang Ilmu Agronomi ISSN $2503-1279$

pada akhir percobaan dengan cara yang dijelaskanoleh Gardner et al. (1991). Bagian akar dan tajuk dibersihkan lalu dikeringkan dengan melakukan pengovenan pada suhu $80^{\circ} \mathrm{C}$ selama 24 jam, setelah itu masing-masing sampel ditimbang. Nisbah tajuk akar dihitung dengan rumus berikut ini; Nisbah tajuk akar $=\frac{\text { Bobot kering tajuk }}{\text { Bobot kering akar }}$ dan 10) Berat Kering Tanaman dilakukan dengan cara menimbang berat kering tanaman dilakukan pada akhir percobaan. Tanaman lada terlebih dahulu dibersihkan dari tanah, kotoran dengan air. Tanaman lada yang telah dibersihkan dimasukkan kedalam oven guna untuk mengeringkan dengan suhu $80{ }^{\circ} \mathrm{C}$ selama 24 jam sampai beratnya konstan. Bahan hasil pengovenan tersebut ditimbang sebagai berat kering tanaman.

Data hasil percobaan dianalisis secara statistika dengan analisis ragam dan dilanjutkan dengan uji Duncan New Multiple Range Test (DNMRT) pada taraf $\alpha$ 5\%.

\section{HASIL DAN PEMBAHASAN}

Hasil analisis ragam secara umum menunjukkan bahwa perlakuan sumber stek berpengaruh terhadap peubah persentase stek hidup, jumlah akar, panjang tunas, panjang akar, jumlah daun, bobot kering akar, bobot kering tajuk dan bobot kering total. Perlakuan sumber stek berpengaruh tidak nyata terhadap peubah jumlah tunas dan rasio tajuk akar. Penjelasan hasil pengamatan disajikan sebagai berikut:

Tabel 1. Pengaruh sumber sulur terhadap rerata stek hidup, jumlah akar, jumlah tunas, panjang tunas dan panjang akar

\begin{tabular}{|c|c|c|c|c|c|}
\hline Sumber Sulur & $\begin{array}{l}\text { Parameter } \\
\text { Stek } \\
\text { Hidup } \\
(\%)\end{array}$ & $\begin{array}{l}\text { Jumlah } \\
\text { Akar } \\
\text { (helai) }\end{array}$ & $\begin{array}{l}\text { Jumlah } \\
\text { Tunas } \\
\text { (helai) }\end{array}$ & $\begin{array}{l}\text { Panjang } \\
\text { Tunas } \\
\text { (cm) }\end{array}$ & $\begin{array}{l}\text { Panjang } \\
\text { Akar }(\mathrm{cm})\end{array}$ \\
\hline Sulur Panjat & $8,50 \quad b$ & $7,00 \quad \mathrm{c}$ & $2,75 \quad \mathrm{c}$ & $9,50 \quad b$ & $8,50 \quad b$ \\
\hline Sulur Buah & 3,25 a & 3,75 a & $1,25 \mathrm{a}$ & 7,25 a & 3,25 a \\
\hline Sulur Gantung & $8,25 \quad b$ & $6,25 \quad b c$ & $2,25 \mathrm{ab}$ & $9,00 \quad b$ & $8,25 \mathrm{~b}$ \\
\hline Sulur Tanah & $7,00 \quad b$ & $5,50 \quad b$ & $2,25 \mathrm{ab}$ & $8,00 \mathrm{ab}$ & $7,00 \quad b$ \\
\hline
\end{tabular}

Keterangan: Angka-angka yang diikuti oleh huruf kecil yang sama berbeda tidak nyata menurut uji DNMRT taraf 95\%

Hasil pengamatan menunjukkan bahwa stek lada dari sulur panjat menghasilkan persentase stek hidup tertinggi yaitu $80 \%$ sedangkan stek dari sulur buah hanya $33 \%$. Data ini mengindikasikan bahwa stek dari sulur panjat memiliki sumber energi (karbohidrat) dan hormon tumbuh endogen paling tinggi yang dapat digunakan stek untuk menumbuhkan calon tunas dan calon akar. Diduga sulur panjat merupakan sulur yang aktif dalam pertumbuhan sehingga stek dari bagian sulur panjat ini dapat tumbuh dengan baik dan seimbang antara akar dan tunas untuk membentuk tanaman baru.

Menurut Budi et al. (2012) bahwa zat pengatur tumbuh yang paling berperan pada pengakaran stek adalah Auksin, sedangkan zat pengatur tumbuh yang paling berperan dalam pembentukan tunas adalah sitokinin. Kandungan auksin dan sitokinin yang seimbang pada stek sulur panjat diduga akan meningkatkan persentase hidup stek asal sulur panjat. Selain itu stek sulur panjat tidak menghabiskan energi untuk menghasilkan bunga sehingga kandungan karbohidrat tetap tinggi sampai stek itu ditanam. Kandungan fotosintat ini tidak lagi tersedot ke calon bunga dan buah, 
Jurnal Media Pertanian Vol. 1 No. 1 Tahun 2016 Hal. 29 - 35

Media Komunikasi Hasil Penelitian dan Review Literatur Bidang Ilmu Agronomi

ISSN $2503-1279$

melainkan tetap tersimpan dalam batang dan daun yang tinggal, sehingga pada saatnya akan digunakan kembali untuk pertumbuhan tunas.

Menurut Djamhuri (2011) cadangan karbohidrat pada tanaman yang merupakan hasil dari keseimbangan proses respirasi dan fotosintesis, perombakannya dapat dikurangi karena tidak ada pembungaan, sehingga memungkinkan tanaman mengakumulasi cadangan makanan. Dengan demikian pada kondisi optimum karbohidrat akan berintegrasi dengan bahan pembangun lainnya. Selanjutnya Harjadi, Darmawan dan Zaubin (1996), menyatakan bahwa korbohidrat berperan dalam meningkatkan pembelahan sel jaringan meristem pada titik-titik tumbuh. Jadi dengan adanya penumpukan cadangan makanan terutama persediaan karbohidrat sangat berpengaruh sekali terhadap muncul tunas. Kafrawi (2007) menyatakan bahwa ketersediaan zat makanan sangat mempengaruhi persentase keberhasilan pertum-buhan bibit asal setek, terutama ketersediaan bahan-bahan pembangun seperti karbohidrat. Kandungan karbohidrat ini dalam setek sangat mempengaruhi sekali terhadap perkembangan tunas dan akar.

Stek sumber sulur buah paling rendah nilai persentase stek hidup, hanya sebesar $33 \%$. Rendahnya kemampuan stek untuk tumbuh dan berkembang karena rendahnya sumber energi yang tersedia pada stek. Diduga sumber energi telah banyak digunakan untuk menumbuhkan bunga dan mengembangkan buah, sehingga bila bagian ini dijadikan sumber stek maka akan menghasilkan persentase stek hidup yang rendah.

Sumber energi yang rendah pada stek sumber sulur buah juga berdampak pada jumlah akar $(3,75$ helai) dan panjang akar $(3,25 \mathrm{~cm})$. Sangat berbeda dengan stek sumber sulur panjat yang memiliki jumlah akar sebanyak 7 helai dan panjang akar 8,50 $\mathrm{cm}$. Beberapa literatur menjelaskan bahwa akar menempati posisi yang sangat penting dalam perkembangan stek. Beberapa aplikasi zat pengatur tumbuh digunakan untuk memacu pertumbuhan akar. Adanya perkembangan akar maka stek dapat mengambil air dari media dan menggunkannya dalam reaksi kimia dalam tubuh tumbuhan dan melepaskannya dalam bentuk uap air. Kegiatan menyerap air dan melepaskannya kembali dalam bentuk uap air sangat penting untuk menjaga kestabilan suhu tubuh tumbuhan untuk menghindari terjadinya kelayuan tanaman. Pembentukan akar terjadi karena adanya pergerakan ke bawah dari auksin, karbohidrat dan zat-zat yang berinteraksi dengan auksin (rooting cofaktor) yang mengakibatkan perakaran, baik yang berasal dari tunas maupun dari daun (Budi et al., 2012). Zat-zat ini akan mengumpul di dasar setek yang selanjutnya akan menstimulir pembentukan akar (Djamhuri, 2012).

Hasil percobaan yang berbeda disampaikan oleh Riduan (2014) bahwa tunas pada stek sangat diperlukan untuk mendorong terjadinya perakaran stek. Pembentukan akar tidak akan terjadi bila seluruh tunas dihilangkan atau dalam keadaan dorman, hal ini terjadi karena tunas berperan sebagai sumber auksin yang menstimulir pembentukan akar, terutama bila tunas mulai tumbuh.

Penyerapan air oleh akar juga berdampak terhadap ketersediaan hara bagi tanaman untuk melaksanakan proses fotosintesis. Percobaan ini digunakan stek dua daun dan ketersediaan hara karena aktivitas akar akan mendorong proses fotosintesis. Proses fotosintesis ini akan menghasilkan makanan yang digunakan oleh stek untuk menumbuhkan tunas dan membentuk daun baru lainnya. Pada stek sumber sulur buah hanya menghasilkan jumlah tunas 1,25 buah, panjang tunas sebesar $7,25 \mathrm{~cm}$ dan jumlah daun 1,25 helai. Sangat berbeda dengan stek dari sulur panjat, dimana jumlah tunas sebanyak 2,75 batang, panjang tunas sebesar 9,50 cm dan jumlah daun 3,25 helai. 
Jurnal Media Pertanian Vol. 1 No. 1 Tahun 2016 Hal. 29 - 35

Media Komunikasi Hasil Penelitian dan Review Literatur Bidang Ilmu Agronomi ISSN $2503-1279$

Perkembangan tunas dan akar yang berbeda pada pertumbuhan stek yang ditunjukkan oleh peubah jumlah akar, panjang akar, panjang tunas dan jumlah daun juga berdampak terhadap peubah bobot kering tunas, bobot kering akar, rasio tajuk akar dan bobot kering total tanaman. Nilai-nilai peubah ini masih mengikuti pola yang sama dimana nilai terendah didapat dari stek sumber sulur buah dan tertinggi dari stek sumber sulur panjat.

Tabel 2. Pengaruh sumber sulur terhadap rerata jumlah daun, bobot kering akar, bobot kering tunas, nisbah tajuk akar dan bobot kering total

\begin{tabular}{|c|c|c|c|c|c|}
\hline Sumber Sulur & $\begin{array}{l}\text { Parameter } \\
\text { Jumlah } \\
\text { Daun } \\
\text { (helai) }\end{array}$ & $\begin{array}{l}\text { Bobot } \\
\text { Kering } \\
\text { Akar (g) }\end{array}$ & $\begin{array}{l}\text { Bobot } \\
\text { Kering } \\
\text { Tajuk (g) }\end{array}$ & $\begin{array}{l}\text { Nisbah Tajuk } \\
\text { Akar }\end{array}$ & $\begin{array}{l}\text { Bobot } \\
\text { Kering } \\
\text { Total (g) }\end{array}$ \\
\hline Sulur Panjat & $3,25 \quad b$ & $0,58 \quad \mathrm{c}$ & $5,99 \quad \mathrm{c}$ & $10,46 \quad b$ & $6,56 \mathrm{c}$ \\
\hline Sulur Buah & $1,25 \mathrm{a}$ & 0,25 a & $2,33 \quad a$ & $9,70 \quad a b$ & $2,69 \quad \mathrm{a}$ \\
\hline Sulur Gantung & $2,75 \quad b$ & $0,57 \mathrm{c}$ & $5,57 \quad c$ & $9,74 \quad a b$ & $6,15 \mathrm{c}$ \\
\hline Sulur Tanah & $3,25 \quad b$ & $0,41 \quad b$ & $3,77 \quad b$ & $9,28 \quad \mathrm{a}$ & $4,18 \quad b$ \\
\hline
\end{tabular}

Keterangan: Angka-angka yang diikuti oleh huruf kecil yang sama berbeda tidak nyata menurut uji DNMRT taraf 95\%.

Terjadinya perbedaan berat kering masing perlakuan karena terdapatnya perbedaan kandungan cadangan makanan dan pertambahan ukuran bagian tanaman antara masing-masing perlakuan tersebut. Hal ini sesuai yang dikemukakan oleh Ridwan (2014) bahwa pemangkasan akan dapat membantu menyediakan bahan setek yang baik yang siap tumbuh sehubungan dengan adanya cadangan makanan yang lebih banyak.

Berat kering mencerminkan status nutrisi tanaman karena berat kering tergantung dari laju fotosintesis.Sedangkan pertumbuhan tanaman menurut Ridwan (2014) ditunjukkan oleh pertambahan ukuran dan berat kering yang tidak balik.Pertambahan ukuran dan berat kering dari suatu organisme mencerminkan bartambahnya protoplasma, yang mungkin terjadi karena pertambahn ukuran maupun jumlah sel. Selanjutnya Wudianto (2004) menyatakan bahwa pertumbuhan adalah hasil kegiatan fisiologi yang mengakibatkan terjadinya pertambahan jumlah sel, yang akan mempengaruhi organ tumbuhan dan komposisi jaringan secara keseluruhan, termasuk berat keringnya.

\section{KESIMPULAN}

Hasil penelitian ini menolak hipotesis nol $\left(\mathrm{H}_{0}\right)$ dan menerima hipotesis $1\left(\mathrm{H}_{1}\right)$ bahwa pertumbuhan bibit lada berbeda antar sumber stek.Penelitian ini juga mendapatkan bahwa stek sumber sulur panjat menghasilkan bibit lada terbaik dan berbeda nyata dibandingkan stek sumber sulur buah, sulur tanah dan sulur gantung.

Dugaan yang mendukung kebaikan stek lada asal sulur panjat adalah kandungan karbohidrat yang tinggi dan adanya keseimbangan hormon endogen auksin dan sitokinin sehingga terjadi kesimbangan pertumbuhan tunas dan akar. Pertumbuhan tunas dan akar inilah yang memacu pertumbuhan stek lada.

\section{DAFTAR PUSTAKA}


Jurnal Media Pertanian Vol. 1 No. 1 Tahun 2016 Hal. 29 - 35

Media Komunikasi Hasil Penelitian dan Review Literatur Bidang Ilmu Agronomi ISSN $2503-1279$

Amanah. S. 2009. Pertumbuhan Stek Lada (Piper nigrum, L.) Berbagai Konsentrasi Auksin. Skripsi, Faperta UNS. Solo.

Aguzean, H. 2009. Respon pertumbuhan bibit stek lada (Piper nigrum, L.) terhadap pemberian air kelapa dan berbagai Jenis CMA. Jurnal Agronomis, Vol 1, No. 1, Maret 2009 ISSN: 1979-8245X

Budi, M.A.I. Donowati dan Dianto.2012. Pengaruh kencing sapi dan air kelapa muda pada pertumbuhan stek lada (Piper nigrum, L.) Jurnal Java Primordial Volume 8, Nomor 1, April 2012

Djamhuri, E. 2011. Pemanfaatan Air kelapa untuk meningkatkan pertumbuhan stek pucuk meranti tembaga (Shorea leprosula Miq.) Jurnal Silvikultur Tropika. Vol. 02 No. 01 April 2011, Hal. 5 - 8. ISSN: 2086-8227

Haryadi, Darmawan dan Zaubin. 1996. Pengaruh jenis setek dan media pembibitanterhadap pertumbuhan bibit tanaman lada (Piper nigrum L.). Bul. Agron. 24(1): 6-9 (1996)

Gardner, F.P, R.B. Pearce dan R.L. Mitchell. 1991. Fisiologi Tanaman Budidaya. Terjemahan H. Susilo.Universitas Indonesia. Jakarta

Gunawan. E. 2014. Perbanyakan tanaman cara praktis dan populer. PT. Agro Media Pustaka. Jakarta selatan.

Kafrawi. 2007. Pertumbuhan setek lada (Piper nigrum L.) yang distimulir dengan hormon tumbuh pada berbagai media tanam organik. Jurnal Agrisistem, Desember 2007, Vol. 3 No. 2. ISSN 1858-4330

Nurhakim, YI. 2014.Perkebunan Lada Cepat Panen. Infra Pustaka. Sukmajaya Depok.

Ridwan, M. 20014. Uji saat pengambilan setek lada (Piper nigrum L.) setelah pemangkasan pohon induk. Stigma Volume XII No.2, April - Juni 2004. 181185 ISSN 0853-3776

Suprato. A. 2001. Auksin Zat Pengatur Tumbuh PentingMeningkatkan Mutu Stek Tanamam. Jurnal Pertanian. Magelang.

Wudianto. R. 2004. Membuat Setek, Cangkok, dan Okulasi. Penebar Swadaya. Jakarta. 